\title{
A Survey-Based Feedback Analysis of the Current Medical Teaching Methodology and Trends in Medical Research Practice in a South Indian Medical Institute
}

Supreeth Nekkanti, Sagarika Manjunath, Arun Mahtani, Archana Meka, Tanushree Rao. ${ }^{1}$

\begin{abstract}
Background: The spine of a good healthcare system is the medical education received by its doctors. The delivery of medical education is evolving continuously. This study was conducted among 541 students in a prestigious medical college in India. The aim of the study was to find out lapses in our current medical education system and steps to improve it. Methods: A total of 541 medical students were included in this study. All undergraduate medical students in second year or above were included in this study. A questionnaire of 20 questions was given to each student and they were asked to mark the answers they felt were most appropriate. The questionnaire dealt with issues faced in our current education system regarding teaching methodology, research, and steps to improve the healthcare system. Data was collected, analyzed and statistically evaluated using Microsoft Excel and SPSS version 21.0. Results: Most students felt that classroom strength should not be more than a hundred students. They felt that more innovative teaching methods and discussions should be included. Students laid emphasis on research and clinical skills training. They felt that the healthcare system also needs tweaking in terms of funding and practicing evidence-based medicine to be on par with healthcare systems across the world. Conclusion: The results of this study resonate with the results of various other studies regarding the delivery of medical education. It takes into account the holistic approach of improving medical education and healthcare rather than focusing on one single aspect.
\end{abstract}

Key Words: Clinical research; Survey analysis; Feedback; Medical education; Teaching; Education [Subheading] (Source: MeSH-NLM).

\section{Introduction}

Medical education and healthcare in India are facing serious challenges with regards to the content and standard of education. The Government of India recognizes health for all as a national goal and looks to produce competent physicians of first contact in trying to achieve this goa (Vision 2015 - Medical council of India. Available: www.mciindia.org/tools/announcement/MCl_booklet.pdf. Accessed on $14 \mathrm{Dec}$ 2011). There is a serious concern in the current medical education system due to the lack of evidence-based teaching. ${ }^{1}$ The Indian population not only requires more doctors but also a good quality of doctors. Focus on the quality of teaching in medical colleges has led to increased use of student services to evaluate the current teaching practices. There has been an evolving trend among professors to shift the focus on teaching from exam-oriented lectures towards clinical based discussions (Vision 2015 - Medical council of India. Available: www.mciindia.org/tools/announcement/MCl_booklet.pdf. Accessed on 14 Dec 2011). A number of teaching methods like power point presentations, animation videos, 3D models, activity-based learning etc. are being employed to appeal to students with different learning styles. However, the effectiveness of these methods cannot be confirmed without a student feedback in the form of student service.

Imparting medical knowledge and ensuring sound foundation in clinical skills and medical knowledge is the safest bet to produce good doctors. With the evolution in medicine, it is essential to evolve our teaching methods to impart medical knowledge to students. Various studies in different medical institutions across India and the world have been conducted to provide an insight as to what would be the ideal methodology according to students, to efficiently grasp the material and skills being taught to them. ${ }^{1}$ These studies had analyzed population of less than 250-300 participants and also had ambiguous conclusions.
The objectives of this study were initiated after interaction with a few students from the second to house surgeons. These students expressed that a necessary change in the teaching system was warranted. The authors decided to test this hypothesis by conducting a survey-based feedback of all the undergraduate students. The aims of this study were to analyze the response of students towards a favorable teaching modality, to identify the influencing qualities of a teacher as perceived by the medical students, to understand the opinion of students with regards to the current status of health care services in our country, and to explore the interest of medical students towards research and its role in evidence-based medicine.

\section{Methods}

The survey-based study was carried out on Bachelor of Medicine and Bachelor of Surgery (MBBS) students of JSS medical college, Mysore, India. The participants included in this study were only medical students of second, third, fourth year MBBS and the house surgeons. All the students were aged between 18 to 23 years. None of them were suffering from any major medical or psychiatric illness.

A questionnaire was designed by the authors, which included 20 questions, the content of which included teaching methodology, aids for teaching, clinical research and its importance in health care. The students were assured about anonymity and confidentiality of their responses provided. A written informed consent was taken from all the students participating in the survey that the responses provided by them were for research and evaluation purpose only. The participants were only instructed to enter the details of their age, gender and current academic year of study. No names were collected to maintain anonymity. This would allow the students to provide honest responses and feedback. Although there could be a possibility for self-selection bias, all the students who matched the inclusion criteria in the

${ }^{1}$ JSS Medical College and Hospital, Mysore, India. 
respective batches were invited to participate in the study. The questionnaire was explained to them, and all were encouraged to mark the responses, they felt was appropriate. Exclusion criteria included: participants with history of psychiatric disorders or not in a position to provide reasonable responses, incomplete responses, and multiple contradictory answers marked for the same question were excluded from this study. In addition, first year students were excluded from the study for not having experienced clinical postings in the hospital. Participants who withdrew consent and did not wish to participate in the study were eliminated from the study.

Data collection: The questions were first self-applied to look for potential flaws or irrelevance to the study objectives. An initial pilot study was done by inviting five students from each batch to provide their response. The opinions of the students were considered before drafting the final questionnaire. One of the four senior authors explained to each participant the nature of the survey, the contents of the questionnaire and the objectives of our survey. Each student was provided with a separate hard copy of the questionnaire and was asked to mark the appropriate answers with pen. The instruction to each student was standardized which included the objectives of our study and elimination criteria were explained if their responses were incomplete. Students were also encouraged to write down their personal response or opinion about a question, if they did not find any of the options appropriate. Only students from second year MBBS to house surgeons were included. The authors felt that first-year students were still fresh to the course and they would be inexperienced to provide a constructive feedback. Also, they would not be exposed to clinical rotation postings in the hospital and hence, excluded from this study.

Data analysis: Data was collected and tabulated in Microsoft Excel. The statistics of this data was drawn using SPSS version 21.0.

\section{Results}

A total of 541 MBBS students who met the inclusion criteria were included in this study. Out of them, $213(39.4 \%)$ were males and 327 (60.6\%) females (Table 1, Figure 1). Our study included 160 students from second year MBBS, 163 students from third year MBBS, 171 students from fourth year MBBS and 46 house surgeons.

Table 1. Distribution of study subjects according to their gender and year of MBBS study.

\begin{tabular}{|cccc}
\hline Batch year & Female $[\mathrm{n}(\%)]$ & Male $[\mathrm{n}(\%)]$ & Total $[\mathrm{n}(\%)]$ \\
$2^{\text {nd }}$ year & $103(31.5)$ & $57(26.8)$ & $160(29.6)$ \\
$3^{\text {rd }}$ year & $97(29.7)$ & $66(31.0)$ & $163(30.2)$ \\
$4^{\text {th }}$ year & $96(29.4)$ & $75(35.2)$ & $171(31.7)$ \\
Intern & $31(9.5)$ & $15(7.0)$ & $46(8.5)$ \\
\hline Total & $327(100.0)$ & $213(100.0)$ & $540(100.0)$
\end{tabular}

Legend: Chi-square: 3.347 , df: 3, p-value: 0.341 , Statistically not significant.

Figure 1. Distribution of Study Population Based on Gender and Year MBBS.

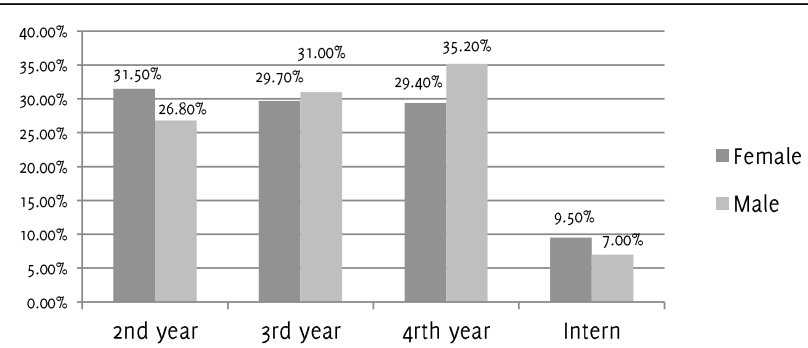

In our analysis, $223(41.2 \%)$ of the students thought that the ideal number of students in a class should be 50 to $100.171(31.6 \%)$ of them preferred class strength of less than 50 students. $349(64.5 \%)$ of the students opined that the average class shouldn't exceed 45 minutes (Figure 2). Only $78(14.4 \%)$ expressed that class duration of one hour was essential. Demonstration was best way to conduct a class according to $295(54.6 \%)$ of the students. Only $110(20.3 \%)$ students found that chalk and blackboard form of teaching helped them in understanding concepts. A majority, $272(50.3 \%)$ of the students, preferred to clear their queries with their friends. $150(27.8 \%)$ of them expressed an anxiety of ridicule if their doubts were expressed in front of the entire class (Table 2).

About $361(66.7 \%)$ of the students thought that medical research is important in a medical institute. About 37 (6.85\%) expressed the contrary (Figure 3). $223(41.2 \%)$ of them thought that the sixth term (third year MBBS) was an ideal time to start a medical research project given the relative free time they had. Almost 177 (32.77\%) thought that the third term (second year MBBS) was an ideal time to start a medical research project. $310(57.3 \%)$ of them were interested in conducting a clinical research project. $121(22.4 \%)$ of them wanted to research on pathogenesis of the diseases. Around $109(20.18 \%)$ of them wanted to research on drugs that would cure current non-treatable conditions like cancer, diabetes, and hypertension. $310(57.3 \%)$ of the students had no orientation on how to start a research project and that was why they had not done a research project yet. $82(15.2 \%)$ of them thought that the professors don't encourage the students enough to conduct a research project. $77(14.25 \%)$ of them thought that resources to conduct a research were limited or not accessible.

More than half of the students $(292,54 \%)$ believed clinical skills were the most important skill to be acquired by a successful doctor (Figure 4, Table 2). 196 (36.2\%) expressed that thorough theory knowledge was critical to become a successful medical practitioner. $217(40.1 \%)$ of the students thought that the basic concepts were not taught to them during clinical postings. The postings included a mixed group of students from different semesters. The students from a lower term found it difficult to cope with concepts taught without the basics. 199 ( $36.8 \%)$ thought that clinical postings in some department were conducted without a patient and seemed more like a theory class. Around $260(48.1 \%)$ of the students opined that exams should be based on multiple choice questionnaire patterns with an oral viva voce. 82 (15.1\%) students expressed there was no need for exams at all (Figure 4).

\section{Discussion}

We conducted a questionnaire-based survey on 541 medical students in a prestigious Medical College of South India. We attempted to perceive the awareness of students regarding medical research. We tried to understand the shortcomings in the current teaching methodology and asked for inputs to improve the same. It is critical to have established teaching syllabus and protocols in place as it involves grooming the future doctors of the country. It is important to train doctors to inculcate the art of scientific thinking. Inventions and progress in medical sciences have been possible only due to original ideas and scientific thinking.

\section{Framework for Classroom Teaching}

A student centric teaching system is the first and foremost step to improve the quality of medical education being imparted to students. In our study, we found that $223(41.2 \%)$ students preferred a class strength of 50-100 students, followed by 170 (31.6\%) who wanted a class strength of less than 50 students. One reason that could substantiate this finding would be to improve the teacher to student ratio and by doing this, students can actively participate in discussions and as we know that active learning is the best possible way to grasp concepts and knowledge. In a study conducted by Maler et al, it was found that as the class size increases, the cognitive and activity scores among students decline. ${ }^{2}$ Hence smaller class strength allows students to gain a holistic perspective to various topics/diseases taught, through these discussions. This has been proved in studies conducted by Pal et al, who discovered that small group teaching had a positive impact in augmenting students' knowledge, attitude and competency about the subject. ${ }^{3}$ Competency levels increased from $13.7 \%$ to $26.9 \%$ after small group teaching was implemented. ${ }^{3}$ 
Figure 2. Favorable Teaching Method.

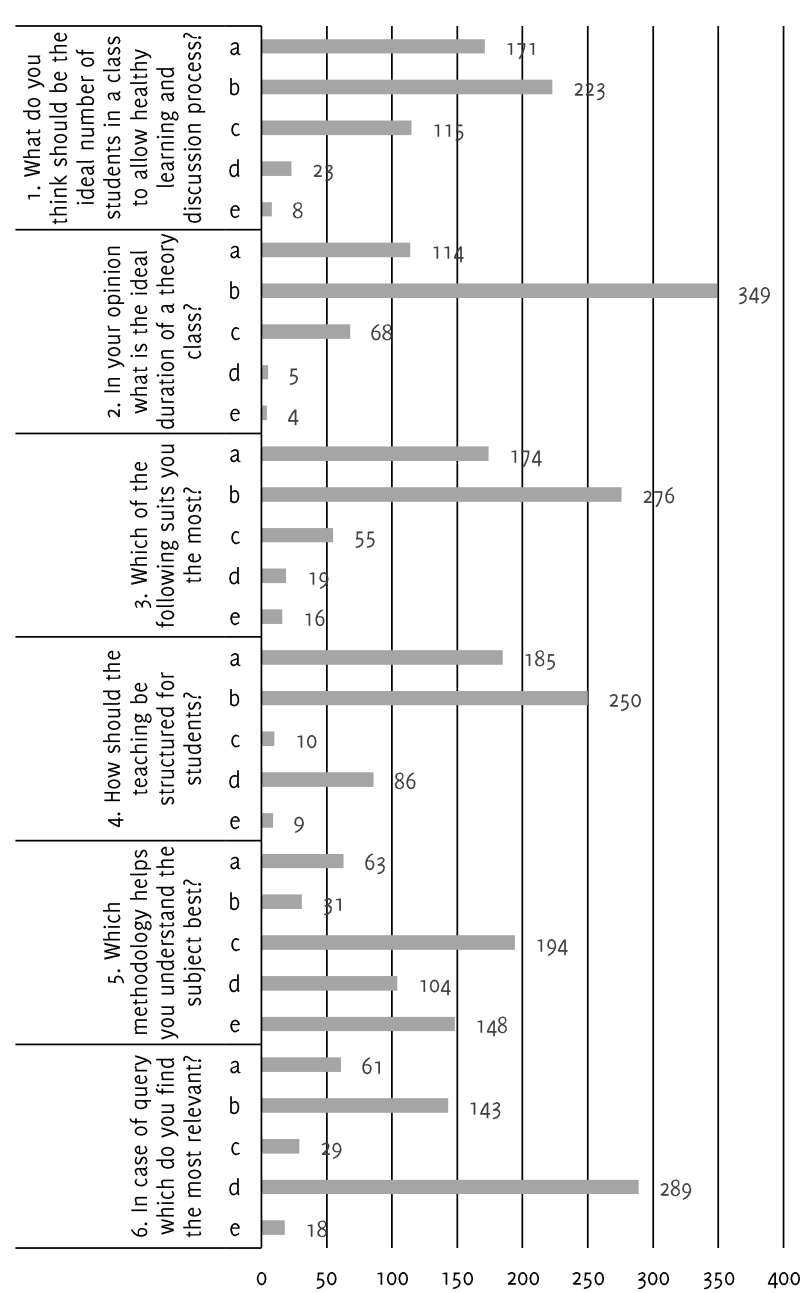

Figure 3. Interest of Medical Students Towards Research.

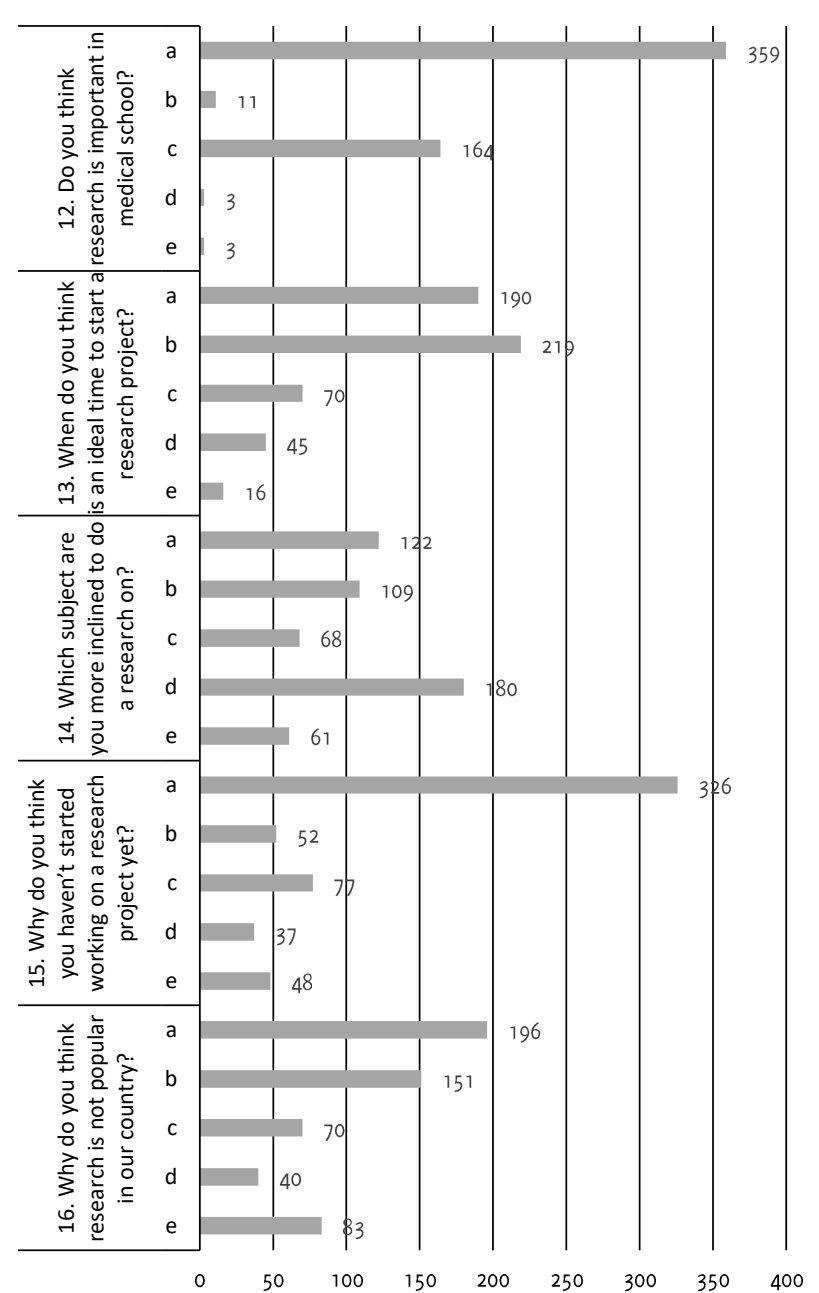

Table 2. Questionnaire Employed in Our Study. Questions 1-6 refer to teaching methods and classes, 7-11 to learning and posting, 12-16 to research, and 17-20 to future projects.

\begin{tabular}{|c|c|c|c|c|}
\hline $\mathrm{N}^{\circ}$ & Options & Question & YES & $\%$ \\
\hline \multirow[t]{6}{*}{1} & & What do you think should be the ideal number of students in a class to allow healthy learning and discussion process? & & \\
\hline & a & Less than 50 & 171 & 31.7 \\
\hline & b & 50-100 & 223 & 41.3 \\
\hline & c & $100-150$ & 115 & 21.3 \\
\hline & $d$ & $150-200$ & 23 & 4.3 \\
\hline & e & Multiple answers & 8 & 1.5 \\
\hline \multirow[t]{6}{*}{2} & & In your opinion what is the ideal duration of a theory class? & & \\
\hline & a & 30 minutes & 114 & 21.1 \\
\hline & $b$ & 45 minutes & 349 & 64.6 \\
\hline & c & $1 \mathrm{hr}$ & 68 & 12.6 \\
\hline & $d$ & 1 and half $\mathrm{hr}$ & 5 & 0.9 \\
\hline & e & Multiple answers & 4 & 0.7 \\
\hline \multirow[t]{6}{*}{3} & & Which of the following suits you the most? & & \\
\hline & a & Classes are extremely important for the learning process & 174 & 32.2 \\
\hline & $\mathrm{b}$ & Classes are critical, but attendance should not be forced upon & 276 & 51.1 \\
\hline & c & Classes maybe relevant only on most frequently tested topics in the exam & 55 & 10.2 \\
\hline & $d$ & I don't need classes, I attend them only for attendance & 19 & 3.5 \\
\hline & e & Multiple answers & 16 & 3.0 \\
\hline \multirow[t]{6}{*}{4} & & How should the teaching be structured for students? & & \\
\hline & a & Clinical Posting 3 hrs, Theory 3 hrs, Practical $1 \mathrm{hr}$ & 185 & 34.3 \\
\hline & $\mathrm{b}$ & Clinical Posting $4 \mathrm{hrs}$, Theory $2 \mathrm{hrs}$, Practical $1 \mathrm{hr}$ & 250 & 46.3 \\
\hline & c & Clinical Posting 2 hrs, Theory 4 hrs, Practical $1 \mathrm{hr}$ & 10 & 1.9 \\
\hline & $d$ & Clinical Posting 2 hrs, Theory $3 \mathrm{hrs}$, Practical $2 \mathrm{hr}$ & 86 & 15.9 \\
\hline & e & Multiple answers & 9 & 1.7 \\
\hline
\end{tabular}




\begin{tabular}{|c|c|c|c|c|}
\hline \multirow[t]{6}{*}{5} & & \multicolumn{3}{|l|}{ Which methodology helps you understand the subject best? } \\
\hline & a & Chalk and board & 63 & 11.7 \\
\hline & b & Power point presentations & 31 & 5.7 \\
\hline & $c$ & Clinical demonstrations on a patient & 194 & 35.9 \\
\hline & $d$ & Use of supplementary aids like animation videos, $3 \mathrm{D}$ illustrations, cadaveric studies etc. & 104 & 19.3 \\
\hline & e & Multiple answers & 148 & 27.4 \\
\hline \multirow[t]{6}{*}{6} & \multicolumn{4}{|c|}{ In case of query which do you find the most relevant? } \\
\hline & a & Teacher has no time for my doubts & 61 & 11.3 \\
\hline & b & Teacher might make fun of me regarding my inadequate knowledge & 143 & 26.5 \\
\hline & $c$ & Teachers don't seem to be updated their knowledge to answer my doubts and dismiss $m$ or change the topic & 29 & 5.4 \\
\hline & $d$ & It's easier to ask to my friends sitting in the first bench & 289 & 53.5 \\
\hline & e & Multiple answers & 18 & 3.3 \\
\hline \multirow[t]{6}{*}{7} & & \multicolumn{3}{|l|}{ Which is the most progressive way to test students with regards to learning process? } \\
\hline & a & The current system of theory and practical & 152 & 28.1 \\
\hline & b & Only Multiple Choice Questions with viva & 74 & 13.7 \\
\hline & c & It should be a daily graded system to assess the regularity, punctuality and learning process of students & 260 & 48.1 \\
\hline & $d$ & We don't need exams & 14 & 2.6 \\
\hline & e & Multiple answers & 40 & 7.4 \\
\hline \multirow[t]{7}{*}{8} & & \multicolumn{3}{|l|}{ In the clinical postings which do you find the most disturbing? } \\
\hline & a & Teacher does not explain concepts from a basic level because the students are from different terms & 231 & 42.8 \\
\hline & b & We are made to sit in an empty room for 3 hours with no learning process & 53 & 9.8 \\
\hline & $c$ & Senior students bully us & 19 & 3.5 \\
\hline & $d$ & There is less patient based teaching and more theory-based teaching & 116 & 21.5 \\
\hline & e & All of the above & 121 & 22.4 \\
\hline & & Multiple answers & & \\
\hline \multirow[t]{6}{*}{9} & & \multicolumn{3}{|l|}{ When do you think basic procedures should be taught to students } \\
\hline & a & Skills should be taught on cadavers in $6^{\text {th }}$ term & 185 & 34.3 \\
\hline & b & Skills should be taught on cadavers in 8 th term & 38 & 7.0 \\
\hline & $c$ & Students should be able to perform procedures in a live patient under supervision in 8 th term & 224 & 41.5 \\
\hline & $d$ & Nothing should be done before internship & 7 & 1.3 \\
\hline & e & Multiple answers & 86 & 15.9 \\
\hline \multirow[t]{6}{*}{10} & & \multicolumn{3}{|l|}{ What do you think is the most critical skill to develop as a clinician treating a patient? } \\
\hline & a & A sound theoretical knowledge of the specialty he/she is in & 90 & 16.7 \\
\hline & b & The art of communicating with patient & 292 & 54.1 \\
\hline & $c$ & Empathizing the patient & 32 & 5.9 \\
\hline & $d$ & Running a thorough laboratory workup for the patient & 9 & 1.7 \\
\hline & e & Multiple answers & 117 & 21.7 \\
\hline \multirow[t]{6}{*}{11} & & Which do you think is the most effective way to train a student in public speaking & & \\
\hline & a & Seminar topics allotted to students & 146 & 27 \\
\hline & b & Clinical presentation of a patient about his medical problems to the consultant doctor & 209 & 38.7 \\
\hline & $c$ & Anchoring in college fests & 13 & 2.4 \\
\hline & $d$ & Oral presentations or poster presentations in speciality conferences & 80 & 14.8 \\
\hline & e & Multiple answers & 92 & 17 \\
\hline 12 & & Do you think research is important in medical school? & & \\
\hline & a & Yes & 359 & 66.5 \\
\hline & b & No & 11 & 2.0 \\
\hline & $c$ & I'm not sure because I've not been in one & 164 & 30.4 \\
\hline & $d$ & Research is not for doctors & 3 & 0.6 \\
\hline & e & Multiple answers & 3 & 0.6 \\
\hline 13 & & When do you think is an ideal time to start a research project? & & \\
\hline & a & $3^{\text {rd }}$ term & 190 & 35.2 \\
\hline & b & $6^{\text {th }}$ term & 219 & 40.6 \\
\hline & $c$ & $8^{\text {th }}$ term & 70 & 13 \\
\hline & $d$ & Now is the best time & 45 & 8.3 \\
\hline & e & Multiple answers & 16 & 3 \\
\hline 14 & & Which subject are you more inclined to do a research on? & & \\
\hline & a & Research at genetic level to understand the etiopathogenesis of a disease & 122 & 22.6 \\
\hline & $\mathrm{b}$ & Research in drugs to find a better cure for existing diseases & 109 & 20.2 \\
\hline & c & $\begin{array}{l}\text { Research in basic sciences and paraclinical sciences to understand variations of normal anatomy and physiology in various } \\
\text { population groups }\end{array}$ & 68 & 12.6 \\
\hline & $d$ & Research in clinical sciences regarding atypical disease patterns and outcomes of surgeries & 180 & 33.3 \\
\hline & e & Multiple answers & 61 & 11.3 \\
\hline 15 & & Why do you think you haven't started working on a research project yet? & & \\
\hline & a & I have no idea how to go about it & 326 & 60.4 \\
\hline & $\mathrm{b}$ & Teachers don't encourage research & 52 & 9.6 \\
\hline & c & Limited available resources and difficulty accessing & 77 & 14.3 \\
\hline & $d$ & Not interested & 37 & 6.9 \\
\hline & $\mathrm{e}$ & Multiple answers & 48 & 8.9 \\
\hline
\end{tabular}




\begin{tabular}{|c|c|c|c|c|}
\hline \multirow[t]{6}{*}{16} & & Vhy do you think research is not popular in our country? & & \\
\hline & a & Hospitals are severely understaffed, and doctors are clinically overworked & 196 & 36.3 \\
\hline & b & There is very poor funding aid by the government towards heath care & 151 & 28.0 \\
\hline & c & Lack of financial incentives to the doctor & 70 & 13 \\
\hline & d & It's easier to follow western data & 40 & 7.4 \\
\hline & e & Multiple answers & 83 & 15.4 \\
\hline \multirow[t]{6}{*}{17.} & & Which of the following do you think is apt for you & & \\
\hline & a & I would like to pursue post-graduation in India because of a patient load & 225 & 41.7 \\
\hline & b & I would like to pursue post-graduation in India because I want to be with my family & 101 & 18.7 \\
\hline & c & I would like to pursue post-graduation in the western countries because of advanced and better quality of patient care & 144 & 26.7 \\
\hline & d & There is no difference between India and western countries $n$ terms of health care & 29 & 5.4 \\
\hline & e & Multiple answers & 41 & 7.6 \\
\hline \multirow[t]{6}{*}{18.} & & Vhy do Indian doctors visit western countries for super specialty training/fellowships & & \\
\hline & a & It looks cool on the visiting card & 28 & 5.2 \\
\hline & b & They are technologically more advanced in health services & 260 & 48.1 \\
\hline & c & They have better clinical experience than Indian doctors & 28 & 5.2 \\
\hline & d & They practice evidence-based medicine with authentic clinical research & 154 & 28.5 \\
\hline & e & Multiple answers & 70 & 13.0 \\
\hline \multirow[t]{6}{*}{19.} & & $\begin{array}{l}\text { Vhy do you think famous people like cricketers, film actors, politicians prefer to receive treatment from doctors/hospitals outside } \\
\text { ndia }\end{array}$ & & \\
\hline & a & They have more money & 28 & 5.2 \\
\hline & b & They believe their standard of care and treatment is better as compared to Indian hospitals & 335 & 62 \\
\hline & c & They have better skilled doctors with updated knowledge & 54 & 10 \\
\hline & d & They are free from media interference & 40 & 7.4 \\
\hline & e & Multiple answers & 83 & 15.4 \\
\hline \multirow[t]{6}{*}{20.} & & What do you think is the most effective way to ensure development and progress in the field of medicine & & \\
\hline & a & Better funding from the government towards health schemes for the patient & 77 & 14.3 \\
\hline & b & Better infrastructure with latest technologies made available in government hospitals & 182 & 33.7 \\
\hline & c & Evidence based medicine from results of research done in an Indian population instead of following western data & 155 & 28.7 \\
\hline & d & We are on par with the world with respect to health care & 9 & 1.7 \\
\hline & e & Multiple answers & 117 & 21.7 \\
\hline
\end{tabular}

Figure 4. About Learning and Posting.

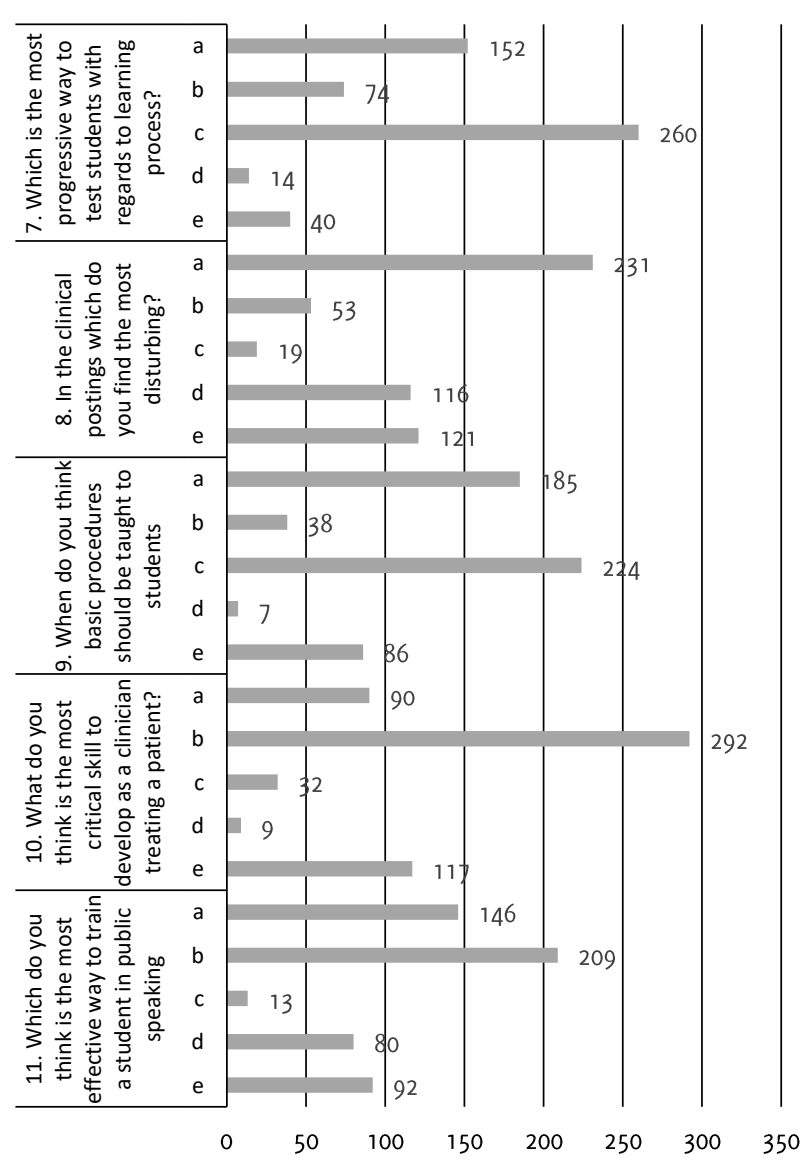

Another aspect to be considered in classroom teaching is the duration of each class. Almost $349(64.5 \%)$ of the students believed that each classroom session should not exceed a time limit of more than 45 minutes. The results expressed in this study correlate with a study carried out by Najmi, in which $54 \%$ of the students felt that timing of lectures should be below 40 minutes. ${ }^{4}$ Another study conducted by Mustafa showed that $54 \%$ of the students felt that timing of the lecture should be reduced and $92 \%$ of the students could not concentrate in class beyond 30 minutes. 5 Hence, the authors feel that in order for the teaching to be effective, high yield conceptual teaching should be practiced in shorter duration of classes.

For active learning to take place, there has to be active teaching. It was a common opinion of students that a few professors lacked the skill of effective teaching. They also expressed that a class was prioritized around completing the curriculum rather than trying to analyze the student's knowledge of the topic taught. Higher percentage of students felt that importance was given to the classes' attendance rather than content learnt from each class. Our study revealed that the students felt that professors needed to be more interactive while teaching; they need to engage students into the subject and should focus on demonstrations rather than PowerPoint presentations/use of blackboard. Our study shows that $292(54 \%)$ of the students prefer demonstrations rather than the latter modes of teaching. On the contrary, various studies done earlier showed that Microsoft PowerPoint $®$ presentation was the preferred method of teaching but that too has faded in the recent times and this just proves to show that the teaching system needs to be continuously updated. The advent of the case-based learning and integrated teaching along with other innovative techniques also seem to have picked up the pace in the recent years as seen in studies conducted by Joshi and Ganjiwale, who conducted an innovative teaching session in a medical college in the state of Gujarat in India. ${ }^{6}$ This teaching methodology was widely accepted by students, $92 \%$ of the students felt that the teaching method was enjoyable and generated more fun and interest among them, $92 \%$ of the students felt that the teaching method implemented 
in the study helped them improve their foundational knowledge about the subject, and $87 \%$ of the students felt that this particular method of teaching helped retain specific information effectively and also wished a similar method would be employed on a regular basis.

Datta et al., studied the use of an interactive response pad to aid teaching in Armed Forces Medical College, Pune, India and found that using this methodology of teaching, students were able to score about 8-10\% higher in the immediate post-test analysis and $15-18 \%$ higher in a test conducted 8-12 weeks later., ${ }^{4,7}$ Zhao et al., conducted a study at the University of lowa comparing lecture-based learning with discussion-based learning among third and fourth year undergraduate medical students. ${ }^{8}$ They found that mean scores for the follow-up practical examination was much higher in the interventional group than in the control group. Students also felt that they were able to manage a case of gastroschisis better in the interventional group and found that discussion-based learning was a worthwhile educational experience for that particular topic. However, there was no difference in the MultipleChoice Questions (MCQ) examination that was conducted among the two groups post the study. Smits et al studied the difference between problem-based learning and lecture-based learning among postgraduate students in the Netherlands. 9 They found out that both methods were favorable but postgraduate students in the problembased learning group had higher performance indicator scores than the group receiving lecture-based learning. Das et al. studied first-year medical students evaluating the effectiveness of clinical exposure in learning respiratory physiology. ${ }^{10}$ The study showed that students performed much better in the post-test analysis when they received clinical exposure than students who did not, with $92 \%$ acceptance rate among students. McMenamin et al., studied body painting as a tool to understand anatomy and found out that body painting promoted knowledge retention and recall through the process of cognitive load by combining the use of color and kinesthetic learning. ${ }^{11,12}$

Bharadwaj et al involved integrated teaching using case-based learning to learn a certain topic. ${ }^{13}$ The sample was divided into two groups one that received the integrated teaching and the other that only received a didactic lecture. They found out that students who received integrated based teaching retained better and scored much better. ${ }^{13}$ From all the aforementioned studies, a message that flashes blatantly is that change in the methodology of teaching is important and teachers of the present generation need to go beyond the conventional methods of teaching to help students understand better and impart knowledge more effectively.

Medicine is vast and challenging. The authors expect students to pose numerous questions and be eager to seek clarifications from the teachers. On the contrary, our study showed that more than half of the students would rather clear their queries with their peers rather than the teacher. The predominant reason was that they were apprehensive about social ridicule in front of the entire class. This led the authors to believe that the teachers must strive to create an encouraging environment for the students to ask their queries. Arguably, the ability of a student to ask questions fearlessly is more to with the student's mindset rather than a change in the teaching pattern. Laughing or mockery of the naivety of a student's question just creates a greater divide between the student and the teacher. The authors feel that it would be ideal for a teacher; to embrace the fact that this is bound to happen and clear queries with utmost patience by gaining the confidence of the students. A study conducted by Arghode et al., showed that empathy plays a role in students' learning and helps improve their performance in the classroom setting. However, the degree to which a teacher should empathize with students is variable depending upon the situation. ${ }^{14}$

\section{Framework for Clinical Postings}

From the second year, a MBBS student's day consists of theory lecture classes, clinical bedside postings and laboratory classes. Our study aimed to find out what would be the perfect balance to conduct al three in a single day. Two hundred fifty-two $(46.5 \%)$ of the students felt that clinical postings should be given utmost importance. They wanted a revision of the time allotted to each component. They felt that acquiring clinical skills rather listening to theory classes was the most important aspect of becoming a good doctor: about 292 (54\%) vs. $195(36 \%)$. Conclusions drawn from the results of our study showed that Clinical Postings should be allotted 4 hours, whereas theory and practical classes should be allotted 2 hours and 1 hour, respectively. In a study conducted by Mustafa, a staggering $83 \%$ of the students felt that lectures should be replaced with clinical sessions because of the smaller strength of the class, active student participation and enhanced clinical orientation and interaction with patients.4 The same was observed in a study conducted by Najmi: $79 \%$ of the students felt that lectures should be replaced by clinical session for similar reasons mentioned above. 5

In our study, students also felt that an alteration in teaching methodology makes clinical postings more efficient. Since a clinical posting class comprises of a mixture of students from all years, it becomes difficult to conduct a class for students with varying levels of knowledge. Our study proves that this form of teaching methodology employed is inefficient as about $216(40 \%)$ of the students felt that they weren't being taught the basics and the students from the fresher years found it difficult to cope with the material being taught to them. A study conducted by Favrat et al., evaluated the implication of bedside teaching in cardiology. They found that $69 \%$ of the residents who received the cardiac auscultation training session could correctly identify murmurs and $62 \%$ could make a correct diagnosis. However, those who did not receive the training session could identify only $40 \%$ of the murmurs and only $21 \%$ could make a correct diagnosis. ${ }^{15}$ In another study conducted among sixth year medical students in Cermany, the authors found that the students who received bedside training under the guidance of a neurologist scored higher in practical and written examination scores $16.3 \% .{ }^{16}$ The authors concluded that it would be effective if bedside clinical teaching was taught from a basic level and the duration of these clinical classes was increased to four hours.

A study conducted by Zakarija-Grkovic and Simunovic implemented the use of objective structured clinical examination (OSCE) for undergraduate students at the University of Split to assess clinical competencies. ${ }^{17}$ A similar model of assessment can be adopted for students of the lower terms instead of them directly handling real patients. This way their foundation will be stronger, and they would be confident to perform the clinical examination on patients.

Students felt that basic procedures should be taught earlier rather than waiting till they reach internship. About $178(33 \%)$ of the students felt that basic procedural training should start from sixth term (third year MBBS) and should be allowed to perform on cadavers. Also, 225 (41.6\%) of the students felt that basic procedural training skills should be taught in the eight terms (fourth year MBBS) on live patients under supervision. This pattern of results is in sync with the study conducted by Zakarija-Grkovic and Simunovic. ${ }^{77}$ Hence the lower term students can be taught skills on models and prepare them for the OSCE whereas the higher term students can be transitioned to demonstrate clinical skills on live patients.

\section{Framework for Research in Medical Education}

Research, the biggest component of medical education, is neglected in our education system. A majority of students $362(67 \%)$ felt that research is an important aspect of medicine and should be included in our curriculum. Almost 314 (58\%) of students were ready to carry out a research project. However, most of them $408(75.43 \%)$ felt that they were not given enough guidance or encouragement on how to do so. Very few students $77(14.25 \%)$ felt that there were limitations in resources to carry out a research project in the form of lack of a 
research guide, knowledge and awareness on how to conduct a research project and evidence-based medicine.

A study conducted by Kotwal proved the same. ${ }^{18}$ With the right guidance and mentorship, the students who submitted projects received approval. Farzaneh et al., conducted a study to identify the restraining factors to conduct research among students in Ardabil University of Medical Sciences in Iran. ${ }^{19}$ Among students, the biggest factor was access to a credible information source and lack of fluency of the English language. Among teachers, the biggest hindrance was administrative barrier and preoccupation with work. However, in our study we did not find any of the aforementioned factors among students.

Another study conducted by Hasan et al revolved around the same issue which was barriers among students in conducting a research project in Isfahan University of Medical Sciences in Iran. ${ }^{20}$ The results of this study were similar to ours. Students felt that they lacked knowledge regarding carrying out a research project or publishing an article in a journal. They also faced problems regarding economic, social, cultural and organizational aspects, which was not the case for the students in our country. They proposed to conduct more workshops regarding research methodologies, article writing and also called out to all the administrators to provide guidance to students willing to carry out a research project. This model can also be adopted by us and will help students gain in depth knowledge and orientation towards research. Another model, which will be useful, is the mentorship program for students similar to the one conducted by Kotwal. ${ }^{19}$ From the above findings we can infer that even though we are at a much better position than other countries to conduct research, we aren't able to do so because of lack of knowledge and proper guidance. Hence, we must concentrate on improving those particular areas so that students can benefit and carry out research projects without facing significant hardships.

\section{Framework for Conducting Examinations}

Our study tried to understand the needs of the medical students on how they would like to be tested. About $260(48.1 \%)$ of students felt that Multiple Choice Questions (MCQS) along with oral Viva Voce was the best way to assess a medical student. The authors feel the current system of theoretical long essays and short essays should be brought to an end because students formulate answers based on memory and not concepts. The length of the answers seems to take precedence over than content of the answer. With MCQs, the students have to understand the tested concept to score well.

A study was conducted at the University of Adelaide by Palmer et al to understand the role of MCQS vs. Modified Essay Questions (MEQS) in testing higher order cognitive skills. ${ }^{21}$ They found that MCQs are better as they tested higher order thinking skills (Modified Bloom's taxonomy class III) much more frequently than MEQs (20\% vs. $2 \%$ respectively) and it stood the test of statistical and intellectual scrutiny when it involved a high-stake exit exam.

\section{Framework for the Future of Medical Education}

In our study, we asked students what would be ideal for their future as a medical professional. We asked them to opine regarding the changes required to help the medical system be on par with the rest of the world. $242(44.8 \%)$ of the students still preferred to stay back in India and pursue their postgraduate education here because of the excellent patient load. About one-third said that they prefer going to other countries to pursue their higher studies (Figure 5).

Almost half of the students $(260,48.1 \%)$ felt that Indian doctors go abroad because the health care services are much better, and they are technologically more advanced compared to India, $216(40 \%)$ of felt that evidence-based medicine and clinical research is being given utmost importance in the west and they feel that it suits their way of practice and learning. A study conducted by Bhatt et al., showed that incidence of migration among medical graduates in Baroda, India is close to $40 \%$ which is similar to the results obtained in our study.22 Among those, $77 \%$ go to the United States and $11 \%$ go to the United Kingdom. The reason for migration is comfortable living conditions and research facilities.

Figure 5. Decision to Pursue Higher Education.

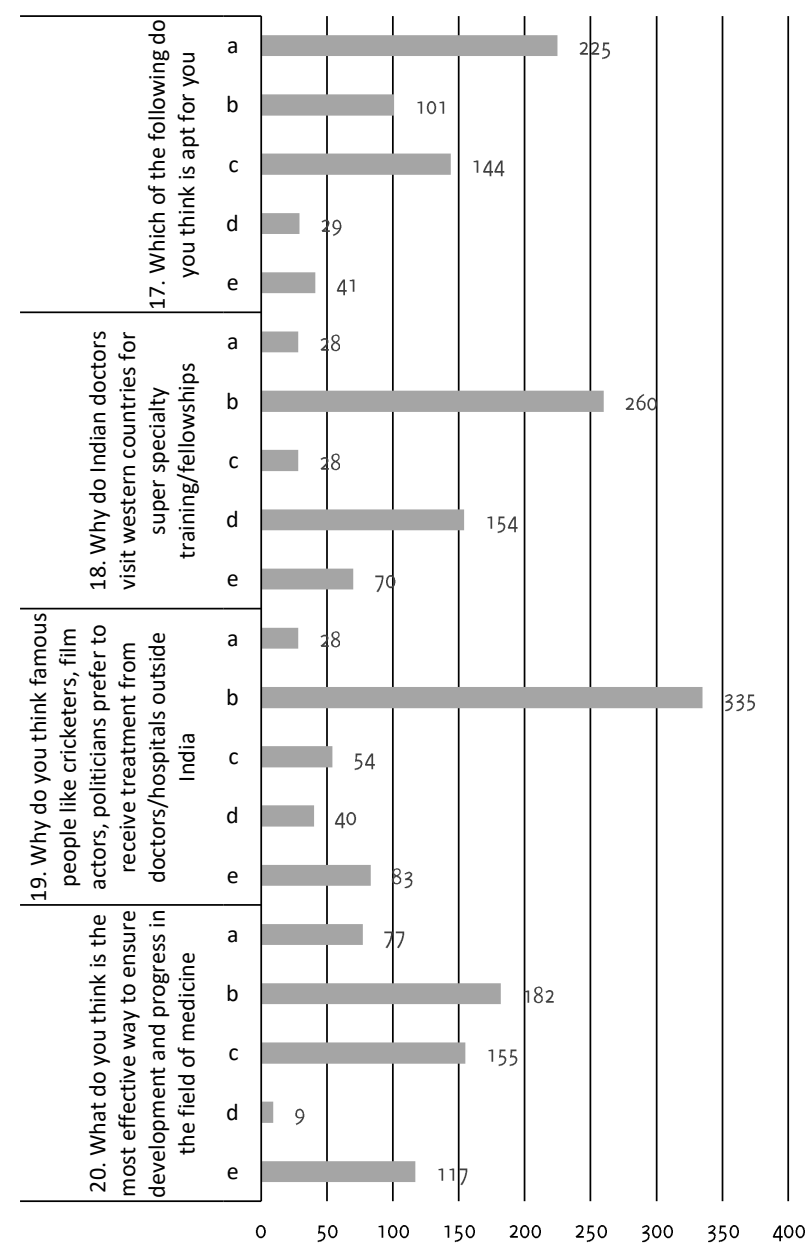

Majority of the students felt that the current system of education in our country should adopt evidence-based medicine and give more importance to clinical research. They also felt that the system needs an influx of more funding from the government to improve health care facilities. If the medical system ever adopts these changes, the issues of brain drain would reduce, and our medical system could be one of the best in the world. A study conducted by Coomaraswamy et al., focused on the impact of evidence-based medicine in postgraduate medical education in the UK. ${ }^{23}$ They found that evidence-based medicine has an edge over standalone teaching as it not only improved knowledge but also improvement in skills, attitude and behavior was observed.

The limitation of this study was in the age of the participants. Although the zeal to innovate is well received by the authors, the authors feel that there could be a possibility of impulsive responses marked by a few students. It is a normal response for a student to dislike classes and the duration of the classes. A balanced gradient-based change would be ideal to transform the current teaching methods. This study was conducted in a single medical institute. Hence, the opinions of this participant group may not however replicate the opinion of the entire South Indian medical population. The authors, however have been trained in various medical institutes across the Indian subcontinent and 


\section{Original Article}

they feel that the problems exposed in the results of this study is real and is well justified and not just an area-based problem.

\section{Conclusion}

The students desire a change in the medical education system. They want the system to evolve and progress, their preference has shifted from the current classroom-based teaching to newer integrative methods and patient-based learning. They are eager to get hands on clinical patient-based experience. Majority of them are extremely interested in medical research but have limited guidance and direction. This study highlights that without proper guidance and mentorship the medical students cannot excel in research-based activities and projects. Finally, the authors concluded that significant changes in the current education system are required to ensure efficient training of medical students. 


\section{References}

1. Lechner SK. Evaluation of Teaching and Learning Strategies. Med Educ Online. 2001 Dec;6(1):4529.

2. Mahler $S$, Neumann L, Tamir P. The class size effect upon activity and cognitive dimensions of lessons in higher education. Assess Eval High Educ. 1986 Mar $1 ; 11(1): 43-59$.

3. Pal R, Kar S, Zaman FA, Jha DK, Pal S. Assessment of impact of small group teaching among students in community medicine. Indian J Community Med. 2012 Jul; $37(3): 170$

4. Najmi RS. Lectures as a Mode of Instruction in Undergraduate Medical Education. J Pak Med Assoc. 1999 Feb;49(2):30-3.

5. Mustafa T, Faroog Z, Asad Z, Amjad R, Badar I, Chaudhry AM, et al. Lectures in medical educaton: what students think?. J Ayub Med Coll Abbottabad. 2014 Jan 1;26(1):21-5.

6. Joshi A, Ganjiwale J. Evaluation of Students' Perceptions Towards An Innovative Teaching-Learning Method During Pharmacology Revision Classes: Autobiography of Drugs. I Clin Diagn Res. 2015 Jul;9(7):FC01-4.

7. Datta R, Datta K, Venkatesh MD. Evaluation of interactive teaching for undergraduate medical students using a classroom interactive response system in India. Med J Armed Forces India. 2015 Jul; 71(3): 239-245.

8. Zhao B, Potter DD. Comparison of lecture-based learning vs discussion-based learning in undergraduate medical students. I Surg Educ. 2016 MarApr;73(2):250-7.

9. Smits PB, D de Buisonjé C, Verbeek JH, van Dijk FJ, Metz JC, Cate 0]. Problembased learning versus lecture-based learning in postgraduate medical education. Scand J Work Environ Health. 2003 Aug;29(4):280-7.

10. Das P, Biswas S, Singh R, Mukherjee S, Choshal S, Pramanik D. Effectiveness of early clinical exposure in learning respiratory physiology among the newly entrant MBBS students. J Adv Med Educ Prof. 2017 Jan; 5(1): 6-10.

11. McMenamin PG. Body painting as a tool in clinical anatomy teaching. Anat Sci Educ. 2008 Jul-Aug; 1(4):139-44.

12. Cookson NE, Aka JJ, Finn CM. An exploration of anatomists' views toward the use of body painting in anatomical and medical education: An international study. Anat Sci Educ. 2018 Mar;11(2):146-154.
13. Bhardwaj P, Bhardwaj N, Mahdi F, Srivastava JP, Gupta U. Integrated teaching program using case-based learning. Int J Appl Basic Med Res. 2015 Aug;5(Suppl 1):S24-8.

14. Arghode V, Yalvac B, Liew J. Teacher empathy and science education: A collective case study. EJMSTE. 2013;9(2):89-99.

15. Favrat B, Pecoud A, Jaussi A. Teaching cardiac auscultation to trainees in interna medicine and family practice: does it work?. BMC Med Educ. 2004 Dec;4(1):5.

16. Heckmann JC, Bleh C, Dütsch M, Lang CJ, Neundörfer B. Does improved problem based teaching influence students' knowledge at the end of their neurology elective? An observational study of 40 students. I Neurol. $2003 \mathrm{Dec}$ 1;250(12):1464-8

17. Zakarija-Grković I, Šimunović VJ. Introduction and preparation of an objective structured clinical examination in family medicine for undergraduate students at the University of Split. Acta Med Acad. 2012 Mar 27;41(1):68-74.

18. Kotwal A. Innovations in teaching/learning methods for medical students: Research with mentoring. Indian J Public Health. 2013 Jul 1;57(3):144.

19. Farzaneh E, Amani F, Taleghani YM, Fathi A, Kahnamouei-aghdam F, FatthzadehArdalani C. Research barriers from the viewpoint of faculty members and students of Ardabil University of Medical Sciences, Iran, 2014. Int J Res Med Sci. $2017 \operatorname{Jan} 2 ; 4(6): 1926-32$

20. Ashrafi-rizi H, Fateme Z, Khorasgani ZG, Kazempour Z, Imani ST. Barriers to research activities from the perspective of the students of Isfahan University of Medical Sciences. Acta Inform Med. 2015 Jun;23(3):155.

21. Palmer EJ, Devitt PG. Assessment of higher order cognitive skills in undergraduate education: modified essay or multiple-choice questions? Research paper. BMC Med Educ. 2007 Dec;7(1):49.

22. Bhatt RV, Soni JM, Patel NF, Doctor PS. Migration of Baroda medical graduates, 1949-72. Med Educ. 1976 |ul 1;10(4):290-2.

23. Coomarasamy A, Khan KS. What is the evidence that postgraduate teaching in evidence based medicine changes anything? A systematic review. BM]. 2004 OC 28;329(7473):1017.

\section{Acknowledgments}

None.

\section{Conflict of Interest Statement it Funding}

The Authors have no funding, financial relationships or conflicts of interest to disclose.

\section{Author Contributions}

Conception and design the work/idea: SN. Collection of data/obtaining results: SN, SM, AM, TR. Analysis and interpretation of data: SN, AM. Contribution of patients or study material: SN, TR. Write the manuscript: SM, AM, AM. Critical revision of the manuscript: SN, AM. Approval of the final version: SN, SM, AM, AM, TR.

\section{Cite as:}

Nekkanti S, Manjunath S, Mahtani A, Meka A, Rao T. A survey-based feedback analysis of the current medical teaching methodology and trends in medical research practice in a South Indian Medical Institute. Int J Med Students. 2018;6(1):6-14. 